\title{
PERFORMANCE ANALYSIS OF AN URBAN BUS AND METRO ROUTE USING COMMUTER SURVEY \& TRAFFIC DATA
}

\author{
B.Brahmaiah ${ }^{1}$ and A.Devi Prasad ${ }^{2}$
}

\begin{abstract}
Delhi has been taken as study area to measure the performance analysis of the bus and multimodal transit route. The main objective of this work is to measure the performance of direct route and multimodal route in terms travel time, travel cost, transfer time, waiting time and line haul time. For this analysis, data was collected as commuter travel survey and traffic data. From the modal split models some performance measures were used to analyse the performance of bus and metro transit system. Such measures as Relative Travel Time (RTT), Relative Travel Cost (RTC), Relative Travel Service (RTS), Inter Connectivity Ratio, Passenger Waiting Index (PWI), and Running Index (RI).
\end{abstract}

\section{RESEARCH REVIEW}

Shaaban and Khalil (2013) investigated the quality of service and passenger's perception regarding various factors such as comfort, convenience, safety, and cleanliness. They collected data through questionnaires to observe the quality of the prevailing bus service. They have also tried to predict the future of bus service in Qatar by developing structural equation modelling (SEM) approach.

Kumar et al. (2013) evaluated the performance of multimodal transportation system (MMTS) in New Delhi. They examined the influence of access and egress times on the total travel time. They further evaluated the performance measures such as Travel Time Ratio, Level of Service, Interconnectivity Ratio, Passenger Waiting Index, and Running Index. Interconnectivity ratio i.e. proportion of access and egress timew.r.t total travel time for various combinations such as Mixed-Metro-Mixed, Walk-Metro-Walk, Walk-Metro-Bus and Walk- Bus-Walk was observed.

\section{Brief Overview of Study Area}

Apart the commuter travel survey to get an overlook of the study area,the study of two lines are considered from same origin to destination. One is the direct bus route (817) and other multimodal transit route from the same origin to destination (Najafgarh to Inderlok), in both routes most of the trips patterns observed are work-based trips. Some of them are leisure trips.

\footnotetext{
${ }^{1}$ Department of Civil Engineering Vignan's Institute Of Information Technology, Visakhapatnam, A.P, India.

${ }^{2}$ Department of Civil Engineering Vignan's Institute Of Information Technology, Visakhapatnam, A.P, India.
} 

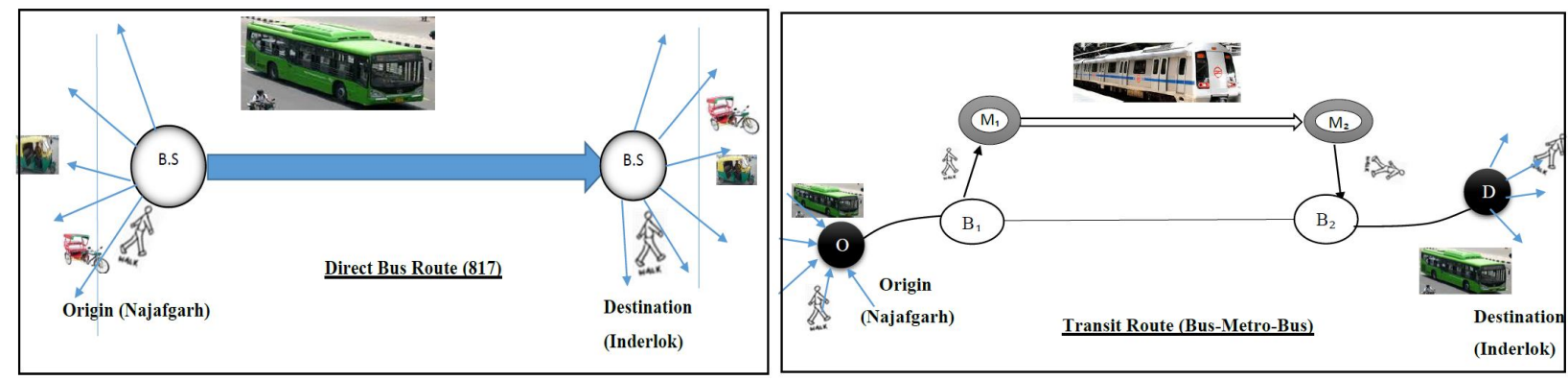

Commuter Survey:For this analysis required large and extensive commuter travel data

i). Personal Information of the passenger: Gender, Age, Income, and Purpose of Trip.

ii). Travel Information of the passenger: Origin, Destination, Access mode and Access time, Egress mode and Egress time, Transfer Time and Wait time at each switch point, In-vehicle time. iii). Passenger Satisfaction Measures in terms of speed, cost, comfort, reliability and transfer.

\section{TRAFFIC DATA COLLECTION}

Table 1.0 shows the volume of traffic flow at various sections in Najafgarh route from Najafgarh to inderlokobserved by dividing the survey into 15 min time periods.

Table 1.0 Composition of Different Class Vehicle at Varies Section from Najafgarh to Inderlok

\begin{tabular}{|l|l|l|l|l|l|l|l|l|}
\hline $\begin{array}{l}\text { Vehicle class } \\
\text { Section No }\end{array}$ & Car & $\begin{array}{l}\text { Two- } \\
\text { Wheeler }\end{array}$ & Bus & Trucks & $\begin{array}{l}\text { Auto } \\
\text { Rickshaw }\end{array}$ & $\begin{array}{l}\text { Cycle } \\
\text { Rickshaw }\end{array}$ & Cycle & $\begin{array}{l}\text { Total } \\
\text { Volume }\end{array}$ \\
\hline 1 & 0.207 & 0.542 & 0.036 & 0.056 & 0.051 & 0.049 & 0.061 & 1780 \\
\hline 2 & 0.185 & 0.552 & 0.028 & 0.006 & 0.139 & 0.044 & 0.046 & 4040 \\
\hline 3 & 0.274 & 0.572 & 0.016 & 0.003 & 0.046 & 0.015 & 0.074 & 4314 \\
\hline 4 & 0.284 & 0.568 & 0.016 & 0.002 & 0.056 & 0.028 & 0.045 & 4119 \\
\hline 5 & 0.283 & 0.562 & 0.019 & 0.001 & 0.068 & 0.035 & 0.033 & 3762 \\
\hline
\end{tabular}

Spot Speed Surveys: Cumulative frequency distribution for each class of the vehicle is plotted and an example of bus as shown in Figure 1.0. From these distributions important parameters namely $15^{\text {th }}$ Percentile Speed $\left(V_{15}\right)$, 50th Percentile Speed $\left(V_{50}\right), 85^{\text {th }}$ Percentile Speed $\left(V_{85}\right)$ and 95th Percentile Speed $\left(V_{95}\right)$ were calculated and values are shown . These data are used as input in simulation program.

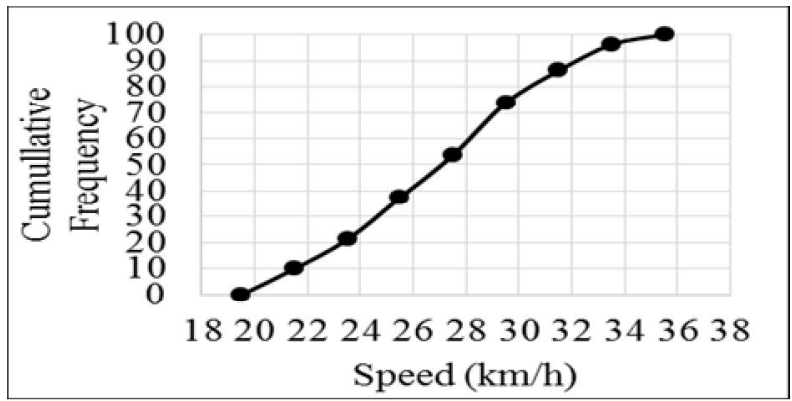

Fig. 1.0 


\section{METHODOLOGY}

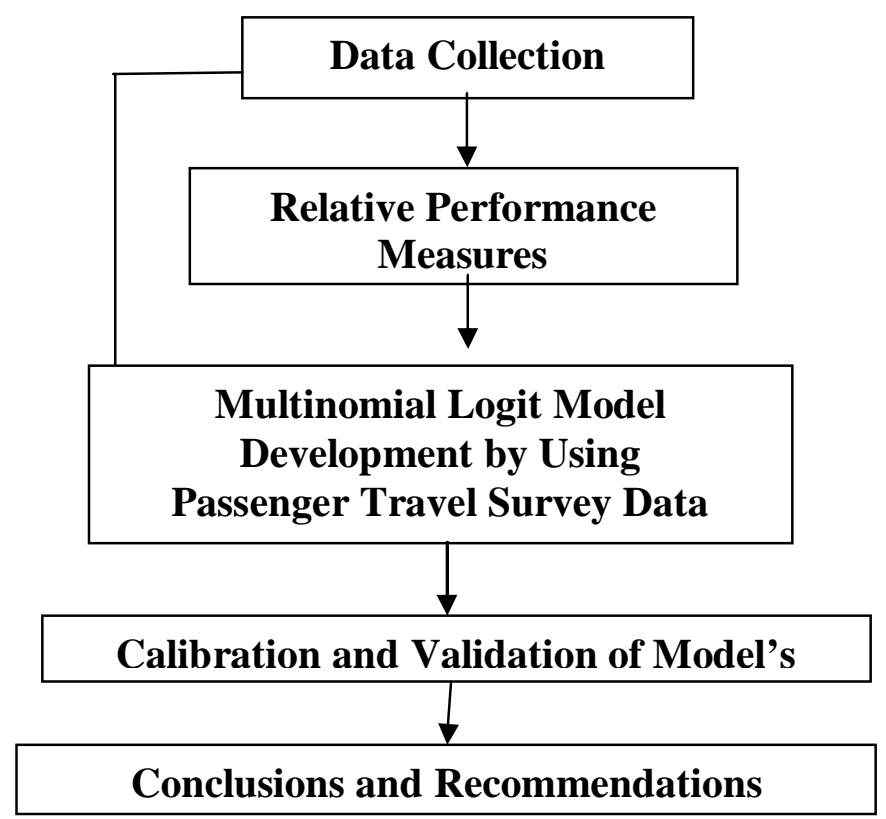

Figure.2.0 - Flow Chart of Methodology for Performance Analysis of Bus and Multimodal Transit Route

\section{PERFORMANCE MEASURES}

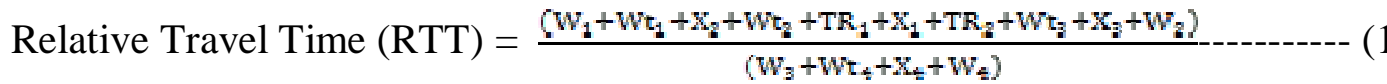

Relative Travel Cost $(\mathrm{RTC})=\frac{\left(\mathrm{C}_{1}+\mathrm{C}_{2}+\mathrm{C}_{2}\right)}{\left\langle\mathrm{C}_{4}\right)}$

Relative Travel Service (RTS) $=\frac{\left(W_{2}+W_{t_{1}}+\mathrm{X}_{2}+W_{t_{2}}+\mathrm{TR}_{2}+\mathrm{TR}_{2}+W_{\mathrm{t}_{2}}+\mathrm{X}_{3}+\mathrm{W}_{2}\right)}{\left(\mathrm{W}_{2}+\mathrm{Wt}_{\mathrm{t}}+\mathrm{W}_{\mathrm{L}}\right)}$

Where

$\mathrm{W}_{1,2,3,4}=\quad$ Walking Time from Home to bus stop, Bus stop to destination, home to nearest bus stop, bus stop to destination

$\mathrm{Wt}_{1} \mathrm{t}_{2} \mathrm{t}_{3} \mathrm{t}_{4}=$ Waiting Time for Bus at Origin, Metro at Transfer Location-1 $\left(\mathrm{M}_{1}\right)$ Bus at Transfer Location, $-2\left(B_{2}\right)$, Bus at Origin (Direct Bus Route)

$\mathrm{X}_{1,2,3,4}=\quad$ Travel Time From Origin to Transfer Location $-1\left(\mathrm{~B}_{1}\right)$, Transfer Location, -1 $\left(\mathrm{M}_{1}\right)$ to Transfer Location, $-2 \quad\left(\mathrm{M}_{2}\right)$,Transfer Location, $-2\left(\mathrm{M}_{2}\right)$ to Destination, Origin to Destination

$\mathrm{C}_{1,2,3,4}=$ Travel Cost of Bus from Origin to $\mathrm{B}_{1}, \mathrm{M}_{1}$ to $\mathrm{M}_{2}, \mathrm{~B}_{2}$ to DestinationOrigin To Destination

\section{UTILITY FUNCTION}

$\mathrm{U}_{\mathrm{i}}=\mathrm{a}_{\mathrm{i}}+\mathrm{a}_{1} \mathrm{x}_{1}+\mathrm{a}_{2} \mathrm{x}_{2}+\mathrm{a}_{3} \mathrm{x}_{3}+\mathrm{a}_{4} \mathrm{x}_{4}$

$\mathrm{u}_{\mathrm{j}}=\mathrm{a}_{\mathrm{j}}+\mathrm{a}_{1} \mathrm{x}_{1}+\mathrm{a}_{2} \mathrm{x}_{2}+\mathrm{a}_{3} \mathrm{x}_{3}+\mathrm{a}_{4} \mathrm{x}_{4}$ 
Where $U_{i}$ and $U_{j}$ is the utility alternatives, $a_{i}$ and $a_{j} i s$ calibrated mode-specific constanst for the same model which represents advantages or disadvantages of mode. $a_{1}$ to $a_{4}$, coefficients are related to variables.

$\mathrm{x}_{1}=$ Waiting Time for mode in minutes

$\mathrm{x}_{2}=$ Travel time (in vehicle time) in minutes

$\mathrm{x}_{3}=\quad$ Travel Cost in Rupees

$\mathrm{x}_{4}=$ Access and Egress Time in minutes

\section{Multinomial Logit Model of Transit Route Choice}

The basic model estimated for predicting transit choice, the discrete choice (multinomial logit) model calculate the probability of choosing mode $i$ if disaggregate, or the proportion of travelers in aggregate case that will select a specific mode according to following relationship. General expression for the probability of choosing an alternative ' $i$ ' $(i=1,2-\cdots$ - $J$ ) from a set of $J$ alternatives is given as

$$
\operatorname{Pr}(b)=\frac{\operatorname{mxp}\left(u_{i}\right)}{\Sigma_{j} \operatorname{sxp}\left(u_{j}\right)}
$$

Where, $\operatorname{Pr}(i)$ is the probability of the decision-maker choosing alternative $i$ and $\mathrm{j}$

\section{RESEARCH OUTCOMES}

\section{Purpose of Trip}

Fig. 3.0 shows that, Four activity categories were observed in this survey, for selected sections.
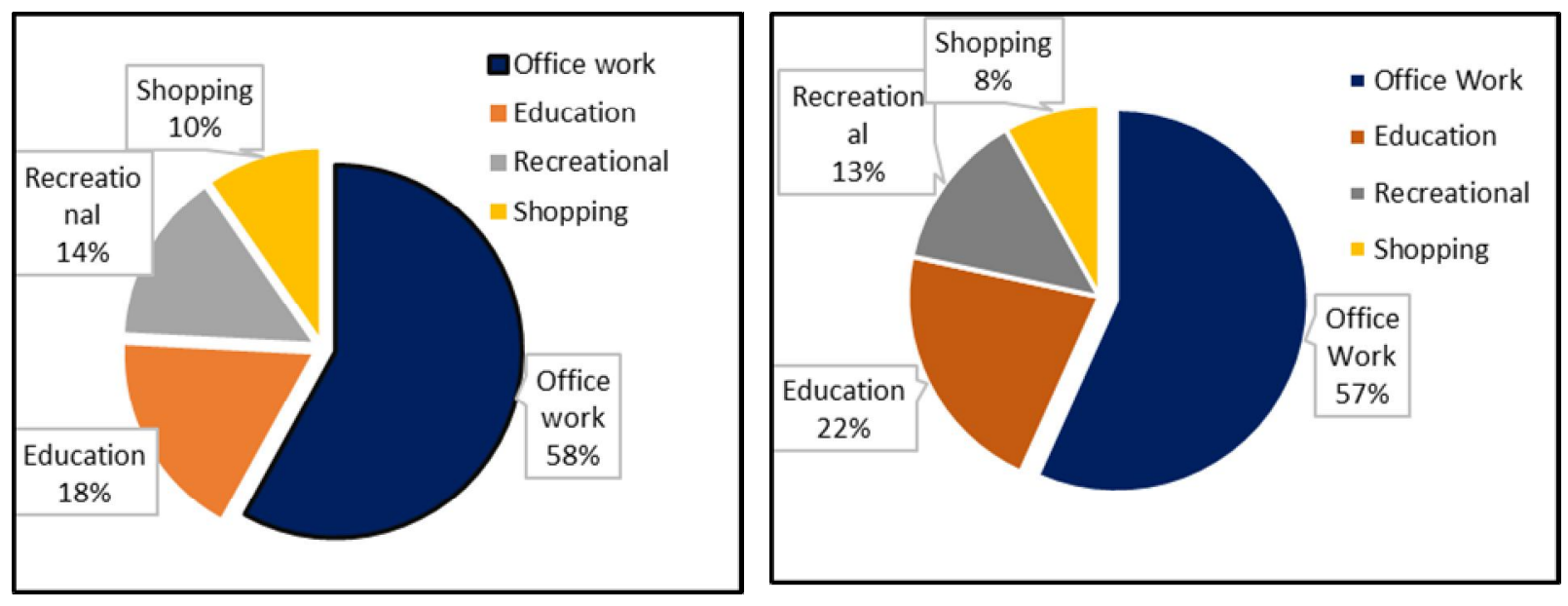

\section{ACCESS AND EGRESS TRAVEL TIMES}

In present study observed access plus egress time vary from 7 to 20 minutes, there is no much variation in both routeaccess and egress travel times as shown in fig. 

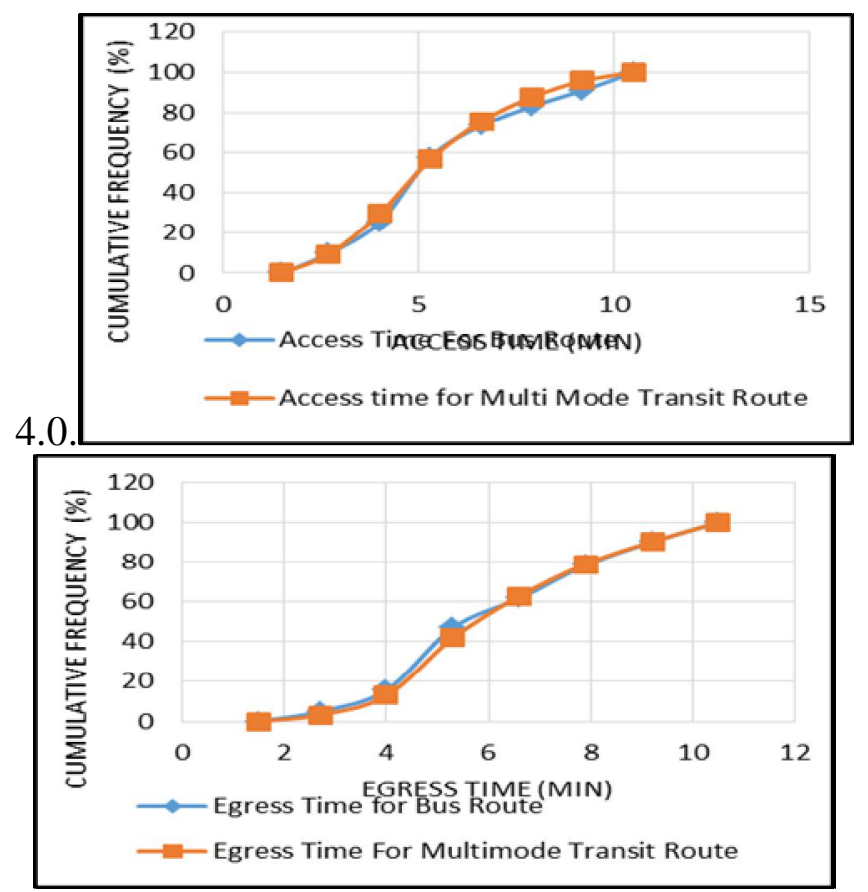

TRANSFERS AND WAITING TIME, TRAVEL COST AND TRAVEL TIME

In passenger trips, transfer time, waiting time, Travel cost and travel times effects the total travel time of passenger and performance of transportation system as shown in fig.5.0. Lower the transfer and waiting time, higher will be the
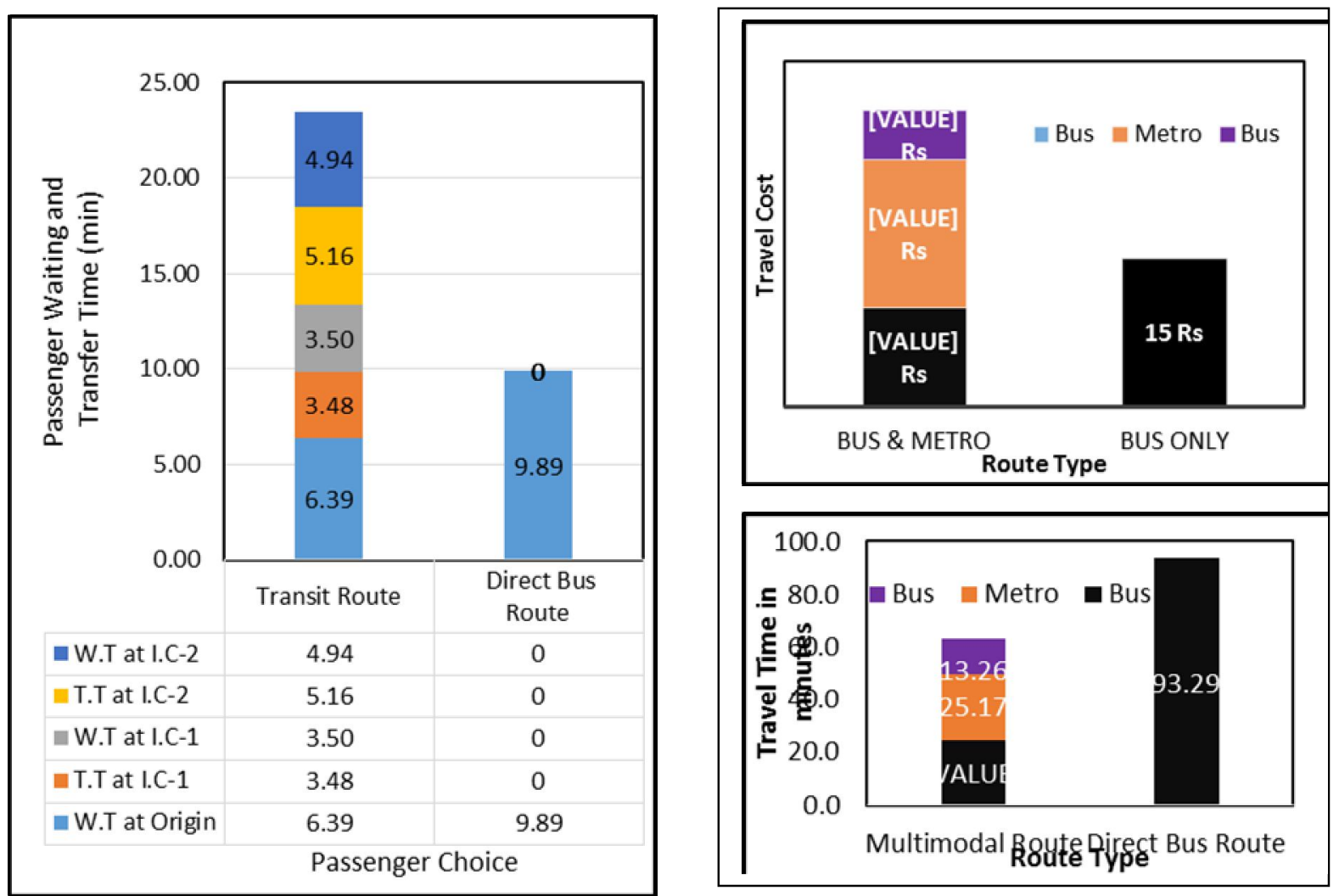
performance of the transport system.

\section{COMMUTER SATISFACTION}

From Fig. 6.0, it can noticed that in multimodal transit route as higher percentage of passengers are satisfied in terms of speed, comfort and reliability than the direct bus route, but in direct bus route passengers are satisfied in terms of cost than the multimodal transit route.

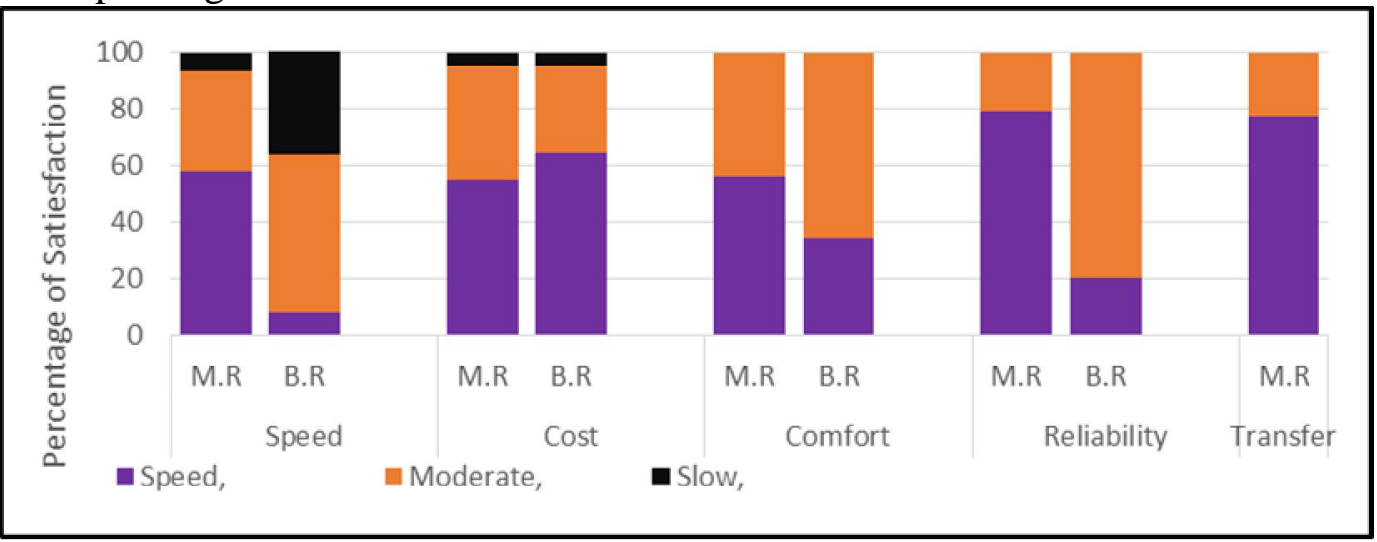

Figure 6.0 Comparison of Commuter Satisfaction

\section{PERFORMANCE MEASURES}

Table 2.0 Performance Measures

\begin{tabular}{|l|l|l|l|}
\hline Indices & Minimum Value & Maximum Value & Mean Value \\
\hline Relative Travel time & 0.622 & 0.0 .974 & 0.861 \\
\hline Relative Travel Services & 2.156 & 5.800 & 3.528 \\
\hline Relative Travel Cost & 2 & 2 & 2 \\
\hline
\end{tabular}

\section{Interconnectivity Ratio}

For Mixed-Metro-Mixed mode trips, the complete value range of interconnectivity ratio falls within the 0.785-0.810 range and the spread in values for chains involving different modes ((Walk+bus) - Metro - (Bus+Walk)) as access/egress modes shown in fig. 7.0.

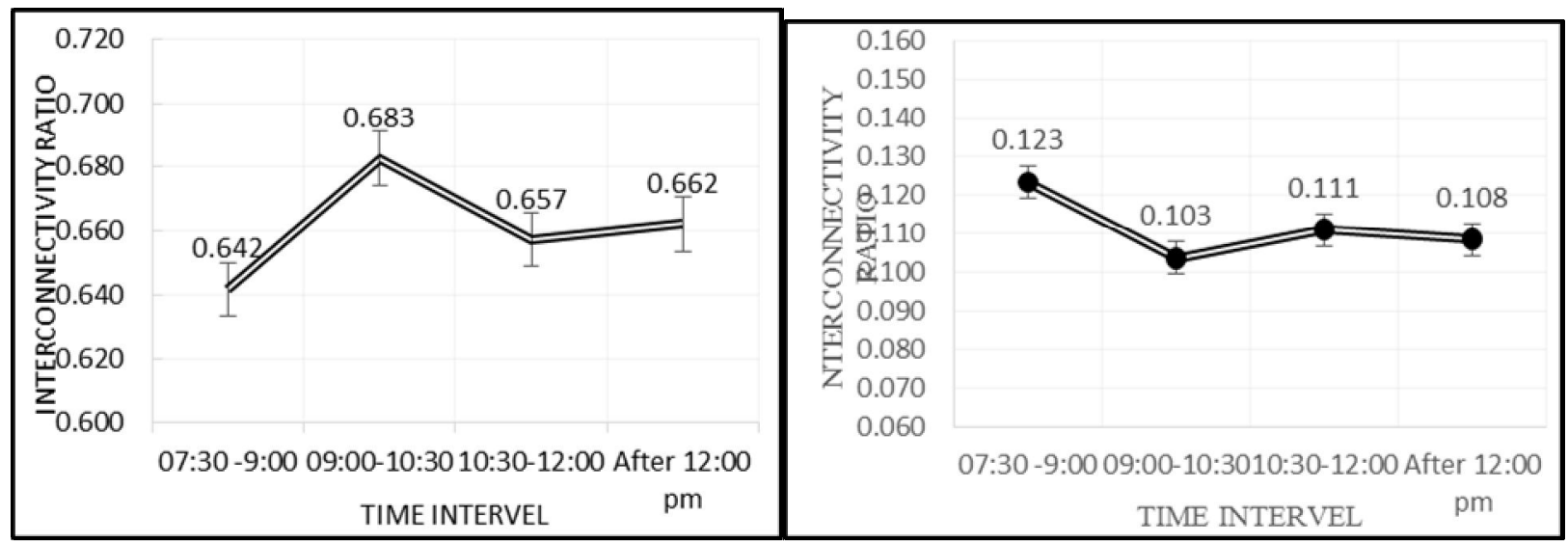

\section{Passenger Waiting Index (PWI)}

The PWI is the ratio of mean passenger waiting time to the frequency of the transport service. PWI can be used to compare the performance of two routes have the same frequency of service. 
The PWI value can be fixed between 0 and 1.Table.3.0 shows PWI value for varies transit modes at transfer locations in multimodal transit route.

Table 3.0 PWI value for various transit modes

\begin{tabular}{|l|l|l|l|}
\hline Transit service & $\begin{array}{l}\text { Mean passenger } \\
\text { waiting time (min) }\end{array}$ & $\begin{array}{l}\text { Frequency of the } \\
\text { transport service (min) }\end{array}$ & PWI \\
\hline $\begin{array}{l}\text { Feeder bus and DTC } \\
\text { (at Origin access service) }\end{array}$ & 6.39 & 10 & 0.639 \\
\hline $\begin{array}{l}\text { Metro (DMRC) (at Transfer } \\
\text { Location-1 Main Mode) }\end{array}$ & 3.0 & 4 & 0.75 \\
\hline $\begin{array}{l}\text { DTC (at Transfer Location-2 } \\
\text { egress service) }\end{array}$ & 4.94 & 8 & 0.617 \\
\hline $\begin{array}{l}\text { DTC (Direct Bus service from } \\
\text { Origin to Destination) }\end{array}$ & 0.618 & 15 & 0.642 \\
\hline
\end{tabular}

\section{RUNNING INDEX (RI)}

Running index (RI) is defined as the ratio of total enroot service time to the total travel time. As RI increases, the efficiency of the system decreases. Its value can be fixed between 0 and 1 . For passengers "satisfaction", its value can be fixed between 0.15 and 0.75 depending upon the number of passenger boarding and alighting at different hours of the day. We observe in this case running index of metro $(0.162)$ is more than running index for the bus $(0.073)$. This means metro is efficiently running and providing proper time for passengers boarding and alighting.

\section{MULTINOMIAL LOGIT MODEL BY USING INTERVIEWED TRAVEL SURVEY DATA}

Table 4.0 shows the Multinomial Logit model estimation parameter results.

Table 4.0Multinomial model estimation results

\begin{tabular}{|l|l|l|l|l|}
\hline Parameters & Coefficients & Standard Error & Z-Value & P-Value \\
\hline Constant & -5.26172 & 2.04067 & -2.58 & .0099 \\
\hline OVTT & -.05151 & .03152 & -1.63 & .0482 \\
\hline IVTT & -.04725 & .01766 & -2.68 & .0074 \\
\hline Travel Cost & .17681 & .10659 & 1.66 & .0572 \\
\hline Age & -.28614 & .30651 & -.93 & .1505 \\
\hline Gender & .58162 & .50817 & 1.14 & .0824 \\
\hline Comfort & .58515 & .42629 & 1.37 & .0699 \\
\hline Reliability & 2.78836 & .45095 & 6.18 & .0000 \\
\hline
\end{tabular}

\section{Utility Equation Derivation}

Depending upon the value of regression coefficient selection of the attribute/ choice set was done for derivation of utility equation

$\mathrm{U}_{\mathrm{M} . \mathrm{R}}$

$=a_{1}+a_{1}($ OVTT $)+a_{2}($ IVTT $)+a_{3}($ Travel Cost $)+a_{4}($ Age $)+a_{5}$ (Gender) $+a_{6}$ (Comfort) + a7 (Reliability) 
$\mathrm{U}_{\mathrm{B} . \mathrm{R}}=\mathrm{a}_{1}$ (OVTT) $+\mathrm{a}_{2}$ (IVTT) $+\mathrm{a}_{3}$ (Travel cost)

Where

$\mathrm{a}_{\mathrm{i}}=$ Utility Constant.

$\mathrm{a}_{1,2,3}=$ Utility coefficient for out vehicle travel time (OVTT), IVTT, Travel Cost

The estimated logit is obtained from the above equation. The equation for utility value of bus route and multimodal transit route come out as following.

$\mathrm{U}_{\mathrm{M} . \mathrm{R}}=-5.26172-.05151 * 24.81-.04725 * 63.30+.17681 * 27.65-.28614 * 2.506+.58162 * 0.707$

$+.58515 * 0.427+2.78836 * 0.427=-3.507$

$\mathrm{U}_{\mathrm{B} . \mathrm{R}}=-5.26172-.05151 * 9.146-.04725 * 96.329+.17681 * 13=-2.724$

\section{Probability of Alternative Route Choice}

Probability of choosing route choice are found below

$\mathrm{P}_{\mathrm{M} . \mathrm{R}}=\frac{e^{\mathrm{Um} \cdot \mathrm{r}}}{e^{\mathrm{Um} \cdot \mathrm{r}}+e^{\mathrm{Ub} \cdot \mathrm{I}}}$

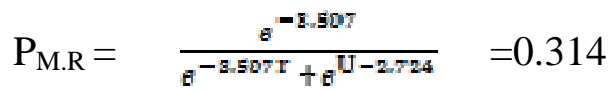

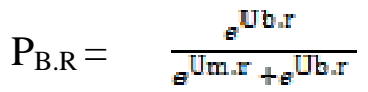

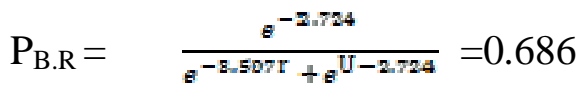

The probability of alternative multimodal transit route being chosen wrt direct bus route would be $=1-0.686=0.314$

\section{Calibration and Validation of Models}

This is presented in Table 5.0. It was seen that predicted percent shares of modes is near to those of observed. The validation sample was 10 percent of the total sample.

Table 5.0 Observed and Predicted Probability of Choice

\begin{tabular}{|l|l|l|l|}
\hline Generation & Choice & $\begin{array}{l}\text { Observed } \\
\text { Probability }\end{array}$ & $\begin{array}{l}\text { Probability Obtained } \\
\text { from equation }\end{array}$ \\
\hline \multirow{2}{*}{ From field data } & Multimodal transit route & 0.378 & 0.314 \\
\cline { 2 - 4 } & Direct bus route & 0.622 & 0.686 \\
\hline
\end{tabular}

\section{CONCLUSIONS}

Route choice is influenced by some factors such as route travel time, travel cost, waiting time, quality of service, personal characteristics etc.

1. From this study RTT says averagely $15 \%$ of travel time will be reduced by multimode transit, as per survey and simulated data. 
2. Passenger choice depends upon the relative travel service ratio, if larger the ratio, the less attractive route becomes as an alternative choice. In this study the average RTS value is 3.528 , revealing multimodal transit route is less attractive than direct bus route.

3. OVTT \& transfer times can be reduced by improving access \& egress facilities, transfer facilities, and card access at public transit systems.

4. The travel time coefficients indicate the negative effect depicting travel time of transit increases, its probability of choosing decreases. The model results demonstrates that

5. Attribute 'age' is having negative impact which means, as age of the individual increases, interest to travel in multimodal transit route reduces.

6. Attributes comfort and reliability are calculating utility for multimodal transit route, their increase in value increases the probability in choosing multimodal transit route.

\section{REFERENCES}

[1]. Shaaban, K. and Rania F.K., (2011), "Investigating the Customer Satisfaction of the Bus Service in Qatar", 2nd Conference of Transportation Research Group of India, Social and Behavioral Sciences 104, PP. 865 - 874.

[2]. P. Phani Kumar., Parida, M, and Mansha Swami. (2013), "Performance Evaluation of Multimodal Transportation Systems", Social and Behavioral Sciences 104. PP.795 - 804.

[3]. Madhav, G.B. and Murtaza, H. (2007), "An analysis of public bus transit performance in Indian cities", Transportation Research Part A. 41, PP.961-981.

[4]. Pawan Kumar and Parida, M. (2011), "Vulnerable Road Users in Multi Modal Transport System for Delhi", PP. 38-46.

[5]. Piet H.L and Lanser, S.H. (2005), "Modelling route choice behavior in multi-modal transport networks" Transportation, Vol. 32, PP. 341-368.

[6]. Agarwal, P. K. and Singh, A.P. (2010), "Performance Improvement of Urban Bus System: Issues and Solution" International Journal of Engineering Science and Technology,Vol. 2(9), PP. 4759-4766 